\title{
Pengaruh budaya organisasi dan motivasi terhadap kinerja karyawan
} pt. grapari telkomsel palangkaraya

\author{
Elisabeth Nauw ${ }^{1)}$, Anike Retawati ${ }^{2)}$ \\ Fakultas Ekonomi dan Bisnis Universitas Palangka Raya
}

\begin{abstract}
Abstrak
Tujuan, - Tujuan penelitian ini untuk memberikan penjelasan tentang pengaruh budaya organisasi, motivasi, dan terhadap kinerja karyawan pada PT. Grapari Telkomsel

Palangkaraya.

Desain/Methodologi/Pendekatan - Metode penelitian yang digunakan adalah pendekatan penelitian kuantitatif. Data yang terkumpul dianalisis dengan menggunakan pendekatan Structural Equation Modelling (SEM) dengan pendekatan Partial Least Square (PLS), software yang digunakan adalah SmartPLS 3,

Temuan penelitian -Hasil penelitian ini menunjukkan bahwa Budaya Organisasi berpengaruh positif dan signifikan terhadap kinerja karyawan, dan motivasi berpengaruh positif dan berpengaruh signifikan terhadap kinerja karyawan..
\end{abstract}

Kata kunci:Budaya Organisasi Dan Motivasi Terhadap Kinerja

The effect of organizational culture and motivation on employee performance of pt. grapari telkomsel palangkaraya

\begin{abstract}
Purpose, - The purpose of this study is to provide an explanation of the influence of organizational culture, motivation, and on employee performance at PT. Grapari Telkomsel Palangkaraya..

Design/methodology/approach - The research method is a quantitative research approach used to obtain data by returning questionnaires that have been filled in by employees. The collected data were analyzed using the Structural Equation Modeling (SEM) approach with the Partial Least Square (PLS) approach, the software used was SmartPLS 3.

Findings - The results of this study indicate that organizational culture has a positive and significant effect on employee performance, and motivation has a positive and significant effect on employee performance..
\end{abstract}

Keywords: Organizational Culture, Motivation, and Employee Performance.

\section{Paper type: Research Paper}

Received, 15 Juni 2021

Revised 22 Juli 2021

Accepted 12 August 2021

Jurnal Manajemen Sains dan Organisasi

Vol 2, No 2, 2021 pp. 106- 115

P-2685-4724; E-2798-9577
Published in the Jurnal Manajemen sains dan Organsasi. Published by FEB UPR Publishing Limited. This article is published under the Creative Commons Attribution (CC BY 4.0) licence. Anyone may reproduce, distribute, translate and create derivative works of this article (for both commercial and non-commercial purposes), subject to full attribution to the original publication and authors. 


\section{Pendahuluan}

Perusahaan merupakan suatu bentuk dari organisasi yang mempunyai berbagai tujuan. Tujuan-tujuan tersebut dapat dicapai melalui pendayagunaan sumber daya manusia yang ada di dalamnya bersama-sama dengan sumber daya lainnya. Kinerja sumber daya manusia (SDM), merupakan faktor yang sangat menentukan dalam keberhasilan suatu organisasi guna mencapai tujuannya, baik itu untuk organisasi berskala besar maupun organisasi kecil. Dalam pengelolaan SDM guna meningkatkan kualitas suatu perusahaan dapat dilakukan dengan meningkatkan kinerja dari SDM itu sendiri, maka perlu diketahui lebih lanjut mengenai peningkatan SDM (Artini, 2019).

Menurut Robbins dan Judge (2012) organisasi itu sendiri merupakan sebuah unit sosial yang dikoordinasi secara sadar, terdiri atas dua orang atau lebih, dan berfungsi dalam suatu dasar yang relatif terusmenerus guna mencapai satu atau serangkaian tujuan bersama, semua tindakan yang diambil dalam setiap kegiatan diprakarsai dan ditentukan oleh manusia yang menjadi anggota perusahaan. Perusahaan membutuhkan adanya faktor sumber daya manusia yang potensial baik pemimpin maupun karyawan pada pola tugas dan pengawasan yang merupakan penentu tercapainya tujuan perusahaan. Sumber daya manusia merupakan tokoh sentral dalam organisasi maupun perusahaan.

Kinerja karyawan yang tinggi sangatlah diharapkan oleh perusahaan tersebut. Semakin banyak karyawan yang mempunyai kinerja tinggi, maka kinerja perusahaan secara keseluruhan akan meningkat sehingga perusahaan akan dapat bertahan dalam persaingan global, untuk itu karyawan dituntut mampu menyelesaikan tugas dan tanggung jawabnya secara efektif dan efisien. Keberhasilan karyawan dapat diukur melalui kepuasan konsumen, berkurangnya jumlah keluhan dan tercapainya target yang optimal. (Regina, 2010).

Kinerja karyawan PT. Grapari Telkomsel juga dapat diukur melalui penyelesaian tugasnya secara efektif dan efisien serta melakukan peran dan fungsinya dan itu 3 semua berhubungan linear dan berhubungan positif bagi keberhasilan suatu perusahaan. Setiap karyawan atau tenaga kerja berharap agar sukses atau berhasil dalam melaksanakan setiap aktivitasnya yaitu mampu menghasilkan kinerja yang tinggi.

Motivasi adalah dorongan, upaya dan keinginan yang ada di dalam diri manusia yang mengaktifkan, memberi daya serta mengarahkan perilaku untuk melaksanakan tugas-tugas dengan baik dalam lingkup pekerjaannya Hakim Dalam Regina (2010). Robbins dan Judge (2014) mendefinisikan motivasi sebagai proses yang ikut Menentukan intensitas arah dan ketekunan individu dalam usaha mencapai sasaran. Kemampuan manusia dapat ditingkatkan dengan memberikan motivasi yang tepat.

PT. Grapari Telkomsel merupakan perusahaan yang bergerak di bidang informasi dan komunikasi serta penyedia jasa dan jaringan telekomunikasi. Dengan berbagai macam layanan yang disediakan, kini Grapari Telkomsel telah melayani jutaan pelanggan di seluruh Indonesia khususnya di Kota Palangka Raya. Oleh karena itu peran sumber daya manusia di PT. Grapari Telkomsel sangat penting agar dapat meningkatkan kualitas produk dan layanannya. Werther dan Davis (Sutrisno, 2016) menyata $\backslash$ kan bahwa sumber daya manusia adalah pegawai yang siap, mampu, dan siaga dalam mencapai tujuan-tujuan organisasi.

PT. Grapari Telkomsel perlu memotivasi karyawan, sehingga karyawan merasa bersemangat untuk bekerja lebih baik dengan budaya organisasi yang solid serta didukung oleh motivasi karyawan sehingga dapat meningkatkan kinerja untuk mencapai tujuan perusahaan.

Berdasarkan deskripsi permasalahan yang sudah dipaparkan pada latar belakang masalah di atas maka penulis tertarik untuk melakukan penelitian dengan judul "Pengaruh 
Budaya Organisasi dan Motivasi Terhadap Kinerja Karyawan PT. Grapari Telkomsel di Kota Palangka Raya.

\section{Kajian Pustaka Kinerja Karyawan}

Kinerja sering kali dijadikan sebagai ukuran prestasi kerja, artinya jika kinerja seseorang baik maka dapat dikatakan orang tersebut berprestasi, atau sebaliknya jika prestasi kerja seseorang baik maka dapat dikatakan berkinerja tinggi. Mangkunegara (2016) istilah kinerja berasal dari kata job performance atau actual performance (prestasi kerja atau prestasi sesungguhnya yang dicapai seseorang). Pengertian kinerja adalah hasil kerja secara kualitas dan kuantitas yang dicapai oleh seorang pegawai dalam melaksanakan tugasnya sesuai dengan tanggung jawab yang diberikan kepadanya. Rozikin (2010).

Menurut Armstrong (2010), kinerja adalah hasil kerja atau prestasi kerja. Kinerja adalah tentang melakukan pekerjaan dan hasil yang dicapai dari pekerjaan tersebut. Kinerja adalah tentang apa yang dikerjakan dan bagaimana cara mengerjakannya.

\section{Budaya Organisasi}

Budaya organisasi merupakan "aturan main" dalam organisasi itu. Budaya organisasi merupakan common understanding atau kebersamaan dari para anggota-anggota organisasi untuk berperilaku sama baik diluar maupun didalam organisasinya.

Menurut Robbins dan Judge (2013) definisi budaya organisasi adalah sebagai berikut:

"Organizational culture refers to a system of shared meaning held by members that distinguishes the organization from other organizations."

Definisi diatas dapat diartikan bahwa budaya organisasi adalah sistem makna bersama yang diselenggarakan oleh anggota yang membedakan organisasi dari organisasi lain.

\section{Motivasi}

Motivasi adalah keinginan untuk melakukan sesuatu dan menentukan kemampuan bertindak untuk memuaskan kebutuhan individu.Menurut Robbins dalam (Suwarto, 2010) menyebutkan bahwa motivasi adalah keinginan untuk berusaha sekuat tenaga untuk mencapai tujuan organisasi yang ditentukan oleh kemampuan usaha untuk memenuhi suatu kebutuhan individu.

Berdasarkan tinjauan pustaka, maka disusunlah kerangka berpikir sebagai sebuah model penelitian untuk menjelaskan bagaimana kinerja pegawai ditentukan oleh pengaruh Budaya organisasi dan Motivasi seperti pada gambar berikut:

Gambar 1. Kerangka Berpikir

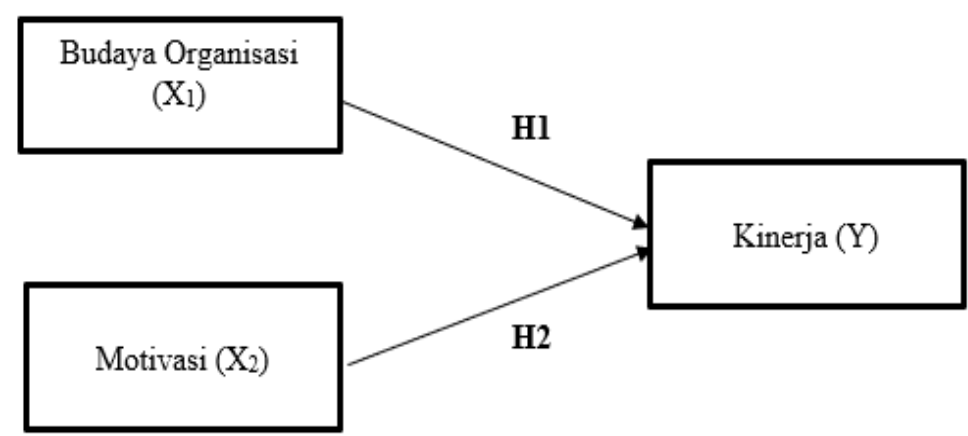




\section{Metode Penelitian}

Pendekatan yang digunakan dalam penelitian ini adalah pendekatan kuantitatif. Pendekatan kuantitatif merupakan pendekatan penelitian yang bekerja dengan angka, datanya berwujud bilangan, dianalisisis menggunakan statistik untuk menjawab pertanyaan atau terhadap hipotesis penelitian yang bersifat spesifik dan untuk melakukan prediksi bahwa suatu variabel tertentu mempengaruhi variabel yang lainnya (Creswell dalam Khodijah (2011).Populasi dalam penelitian ini adalah seluruh karyawan yang bekerja pada PT Grapari Telkomsel di Kota Palangka Raya, Yaitu sebanyak 115 Orang Karyawan.

Sampel merupakan subset dari sebuah populasi, terdiri dari beberapa anggota populasi (Ferdinand, 2014). Teknik pengambilan sampel yang akan digunakan dalam penelitian ini adalah sampling jenuh, yaitu teknik pengambilan sampel apabila semua populasi digunakan sebagai sampel dan dikenal juga dengan istilah sensus (Sugiyono, 2014). Sampel Merupakan Bagian kecil dari suatu populasi. Penentuan sampel dalam penelitian ini mengacu pada pendekatan Yamane (dalam Ferdinand,2014), dengan rumus:

$$
\begin{aligned}
& \mathrm{n}=\frac{N}{1+N e^{2}} \\
& \mathrm{n}=\text { Jumlah Sampel } \\
& \mathrm{N}=\text { Ukuran Sampel } \\
& \mathrm{e}=\text { Tolerin Error Tingkat kesalahan sampel (sampling error), biasanya } 5 \% \\
& \mathrm{n}=\frac{N}{1+N e^{2}} \\
& \mathrm{n}=115 /(1+115(5 \%) 2 \\
& \mathrm{n}=115 /(1+115 .(0,05) 2 \\
& \mathrm{n}=115 /(1+115(0,0025) \\
& \mathrm{n}=115 /(1+) 0,2875 \\
& \mathrm{n}=115 / 1,2875 \\
& \mathrm{n}=89,3 \Rightarrow \text { Digenapkan menjadi } 90 \text { Karyawan }
\end{aligned}
$$

Jenis penelitian ini termasuk dalam kategori penelitian explanatory. Menurut Singarimbun dan Effendi (2012) Menjelaskan explanatory research yaitu penelitian yang digunakan untuk menjelaskan hubungan kausal antara variabel-variabel melalui pengujian hipotesa yang dirumuskan atau sering kali disebut sebagai penelitian penjelas. Penelitian ini memiliki tingkat yang tinggi karena tidak hanya mempunyai nilai mandiri maupun membandingkan tetapijuga berfungsi untuk menjelaskan, meramalkan, dan juga mengontrol suatu gejala dengan pendekatan kuantitatif. pada penelitian ini skala Likert digunakan untuk mengetahui bagaimana sikap, pendapat, dan persepsi responden tehadap vaiabel Budaya organisasi dan Motivasi terhadap Kinerja karyawan PT Grapari Palangkaraya.

Tabel 1. Tabel Skala Likert

\begin{tabular}{|c|c|}
\hline Keterangan & Bobot Nilai \\
\hline Sangat setuju & 5 skor \\
\hline Setuju & 4 skor \\
\hline Netral & 3 skor \\
\hline Tidak setuju & 2 skor \\
\hline Sangat Tidak setuju & 1 skor \\
\hline
\end{tabular}


Sebagai bahan interprestasi hasil dari analisis deskriptif, maka kategori Sangat Setuju sampai dengan Sangat Tidak Setuju (skala likert) menggunakan skala interval, dengan rumus:

Interval $=\frac{\text { Nilai tertinggi-Nilai } \text { Terindah }}{\text { Jumlah } \text { kelas Interval }}=\frac{5-1}{5}=$

\section{Hasil Dan Pembahasan}

Tabel 2. Hasil Uji

Validitas

\begin{tabular}{|c|c|c|}
\hline Uji Validitas & Parameter & Rule of Thumb \\
\hline \multirow[t]{3}{*}{$\begin{array}{l}\text { Validitas } \\
\text { Convergent }\end{array}$} & Loading Factor & $\begin{array}{l}\square>0,70 \text { untuk confirmatory research } \\
\square>0,60 \text { untuk exploratory research }\end{array}$ \\
\hline & Communality & $\begin{array}{l}\square>0,50 \text { untuk confirmatory dan } \\
\text { exploratory research }\end{array}$ \\
\hline & $\begin{array}{l}\text { AVE (Average } \\
\text { Variance } \\
\text { Extracted })\end{array}$ & $\begin{array}{l}>0,50 \text { untuk confirmatory dan } \\
\text { exploratory research }\end{array}$ \\
\hline \multirow{2}{*}{$\begin{array}{l}\text { Validitas } \\
\text { Discriminant }\end{array}$} & Cross Loading & $>0,70$ untuk setiap variabel \\
\hline & $\begin{array}{l}\text { Akar kuadrat Ave } \\
\text { dan korelasi antar } \\
\text { konstruk laten }\end{array}$ & $\begin{array}{l}\text { Akar kuadrat AVE }>\text { korelasi antar } \\
\text { konstruk laten }\end{array}$ \\
\hline
\end{tabular}

Pengujian hipotesis dilakukan dengan menggunakan uji t (t-test) pada tiap-tiap jalur pengaruh antara variabel independen dan dependen serta antara variabel independen dengan variabel dependen melalui variabel moderating. Hasil perhitungan jalur (path) secara keseluruhan dapat dilihat pada path coefficient dan total effects. Pengujian hipotesis dalam penelitian ini menggunakan model persamaan struktural Smart PLS 3.3.2. Hasil pengujian hipotesis menunjukkan hasil keputusan menerima atau menolak hipotesis dengan membandingkan antara t-tabel dengan t-statistik, dan $\mathrm{p}$ values pada tingkat signifikansi dibawah 5\%.

Tabel 3. Hasil Analisis dengan menggunakan validitas konvergen

\begin{tabular}{|c|c|c|c|}
\hline & $\begin{array}{c}\text { Budaya } \\
\text { Organisasi (X1) }\end{array}$ & $\begin{array}{c}\text { Motivasi } \\
(\mathrm{X} 2)\end{array}$ & $\begin{array}{c}\text { Kinerja } \\
\text { Karyawan (Y) }\end{array}$ \\
\hline X1.1 & 0,789 & & \\
\hline X1.2 & 0,624 & & \\
\hline X1.3 & 0,714 & & \\
\hline X1.4 & 0,676 & & \\
\hline X1.5 & 0,732 & & \\
\hline X1.6 & 0,640 & & \\
\hline X1.7 & 0,736 & & \\
\hline X2.1 & & 0,825 & \\
\hline X2.2 & & 0,674 & \\
\hline X2.3 & & 0,837 & \\
\hline X2.4 & & 0,615 & \\
\hline X2.5 & & 0,884 & \\
\hline X2.6 & & 0,647 & \\
\hline X2.7 & & 0,798 & \\
\hline Y1.1 & & & \\
\hline Y1.2 & & & \\
\hline & & & \\
\hline & & & \\
\hline & & & \\
\hline & & & \\
\hline & & & \\
\hline & & & \\
\hline & & & \\
\hline & & & \\
\hline & & & \\
\hline & & & \\
\hline
\end{tabular}


Tabel 4. Nilai Average

Variance Extracted (AVE)

\begin{tabular}{|c|c|c|c|}
\hline & $\begin{array}{c}\text { Budaya } \\
\text { Organisasi (X1) }\end{array}$ & $\begin{array}{c}\text { Motivasi } \\
(\mathrm{X} 2)\end{array}$ & $\begin{array}{c}\text { Kinerja } \\
\text { Karyawan }(\mathrm{Y})\end{array}$ \\
\hline Y1.3 & & & 0,748 \\
\hline Y1.4 & & & 0,839 \\
\hline Y1.5 & & & 0,578 \\
\hline Y1.6 & & & 0,783 \\
\hline
\end{tabular}

\begin{tabular}{llll}
\hline & $\begin{array}{l}\text { Budaya } \\
\text { Organisasi }\end{array}$ & Motivasi & Kinerja Pegawai \\
\hline $\begin{array}{l}\text { Budaya } \\
\text { Organisasi }\end{array}$ & 0,656 & \\
Motivasi & 0,757 & \\
Kinerja Pegawai & & 0,639 \\
\hline Sumber: data diolah, 2021 &
\end{tabular}

Nilai AVE (Average Variant Extracted) budaya organisasi,motivasi dan kinerja karyawan $\geq 0,50$. Dengan demikian dapat dinyatakan bahwa indikator variabel penelitian layak atau valid.

\section{Uji Validitas Diskriminan}

Pengujian ini akan dilihat nilainya menggunakan cross loading. Suatu indikator dinyatakan memenuhi syarat discriminant validity apabila cross loadings indikator pada variabelnya adalah terbesar dibandingkan pada variabel lainnya.

Tabel 5. Nilai Cross Loading

\begin{tabular}{|c|c|c|c|}
\hline & $\begin{array}{c}\text { Budaya } \\
\text { Organisasi (X1) }\end{array}$ & Motivasi (X2) & $\begin{array}{c}\text { Kinerja } \\
\text { Karyawan (Y) }\end{array}$ \\
\hline X1.1 & 0,789 & & \\
\hline X1.2 & 0,624 & & \\
\hline X1.3 & 0,714 & & \\
\hline X1.4 & 0,676 & & \\
\hline X1.5 & 0,732 & & \\
\hline X1.6 & 0,640 & & \\
\hline X1.7 & 0,736 & & \\
\hline X2.1 & & 0,825 & \\
\hline X2.2 & & 0,674 & \\
\hline X2.3 & & 0,837 & \\
\hline X2.4 & & 0,615 & \\
\hline X2.5 & & 0,884 & \\
\hline X2.6 & & 0,647 & \\
\hline X2.7 & & 0,798 & 0,847 \\
\hline Y1.1 & & & 0,748 \\
\hline Y1.2 & & & 0,578 \\
\hline Y1.3 & & & \\
\hline Y1.4 & & & \\
\hline Y1.5 & & & \\
\hline Y1.6 & & & \\
\hline
\end{tabular}

Sumber: data diolah, 2021 


\section{Uji Reabilitas}

Pengujian ini akan dilihat dari hasil nilai cronbach's alpha dan composite reliability. Suatu indikator dikatakan reliable atau memenuhi syarat cronbach's alpha dari masing-masing variabel penelitian harus $\geq 0,60$.

Tabel 6. Nilai composite reliability

\begin{tabular}{|l|l|l|l|}
\hline & $\begin{array}{l}\text { Cronbach's } \\
\text { Alpha }\end{array}$ & rho_A & $\begin{array}{l}\text { Composite } \\
\text { Reliability }\end{array}$ \\
\hline $\begin{array}{l}\text { Budaya } \\
\text { Organisasi (X1) }\end{array}$ & $\mathbf{0 , 8 9 2}$ & $\mathbf{0 , 8 9 6}$ & $\mathbf{0 , 9 2 6}$ \\
\hline Motivasi (X2) & $\mathbf{0 , 7 3 7}$ & $\mathbf{0 , 7 3 9}$ & $\mathbf{0 , 8 5 1}$ \\
\hline Kinerja Pegawai (Y) & $\mathbf{0 , 8 5 8}$ & $\mathbf{0 , 8 6 1}$ & $\mathbf{0 , 8 9 8}$ \\
\hline Sumber: data diolah, 2021 & & & \\
\hline
\end{tabular}

Nilai cronbach's alpha dari masing-masing variabel penelitian $\geq 0,60$. Dengan demikian hasil ini dapat menunjukkan bahwa masing-masing variabel penelitian telah memenuhi persyaratan nilai cronbach's alpha, sehingga dapat dinyatakan bahwa variabel memiliki tingkat reliabilitas yang baik, dan dapat diterima. Nilai composite reliability variabel penelitian $\geq 0,70$. Hasil ini menunjukkan bahwa masing-masing variabel telah memenuhi composite reliability sehingga dapat dinyatakan bahwa variabel penelitian memiliki tingkat reliabilitas yang baik dan dapat diterima.

\section{Model Struktural Inner Model}

Tabel 7. Hubungan antara variabel berdasarkan nilai yang didapat dari path coefficient

\begin{tabular}{|l|l|l|l|l}
\hline Variabel & T-Statistics & P-Values & Hipotesis & Keterangan \\
\hline $\mathrm{X} 1=>\mathrm{Y}$ & $9.955>1,679$ & $0,000<0,05$ & $\mathrm{H} 1$ & Diterima \\
\hline $\mathrm{X} 2=>\mathrm{Y}$ & $6,048>1,679$ & $0,000<0,05$ & $\mathrm{H} 2$ & Diterima \\
\hline
\end{tabular}

Sumber: Pengolahan data dengan PLS, 2021

\begin{tabular}{|l|l|l|}
\hline & R Square & R Square Adjusted \\
\hline Kinerja Pegawai (Y) & 0,928 & 0,921 \\
\hline
\end{tabular}

Tabel 8. Uji Model

Goodness Of Fit

Sumber: Pengolahan data dengan PLS, 2021

Diketahui hasil analisis dengan metode bootstrapping diperoleh nilai R-Square untuk variabel kinerja (Y) sebesar 0,928. Artinya variabel kinerja karyawan (Y) dipengaruhi oleh variabel motivasi (X1) dan budaya organisasi (X2).

\section{Model Struktural (Inner Model)}

Pengujian inner model atau model struktural dilakukan untuk melihat hubungan antara konstruk, nilai signifikansi dan R-square dari model penelitian. Model struktural dievaluasi dengan menggunakan R-square untuk konstruk dependen uji t serta signifikansi dari koefisien parameter jalur struktural. 


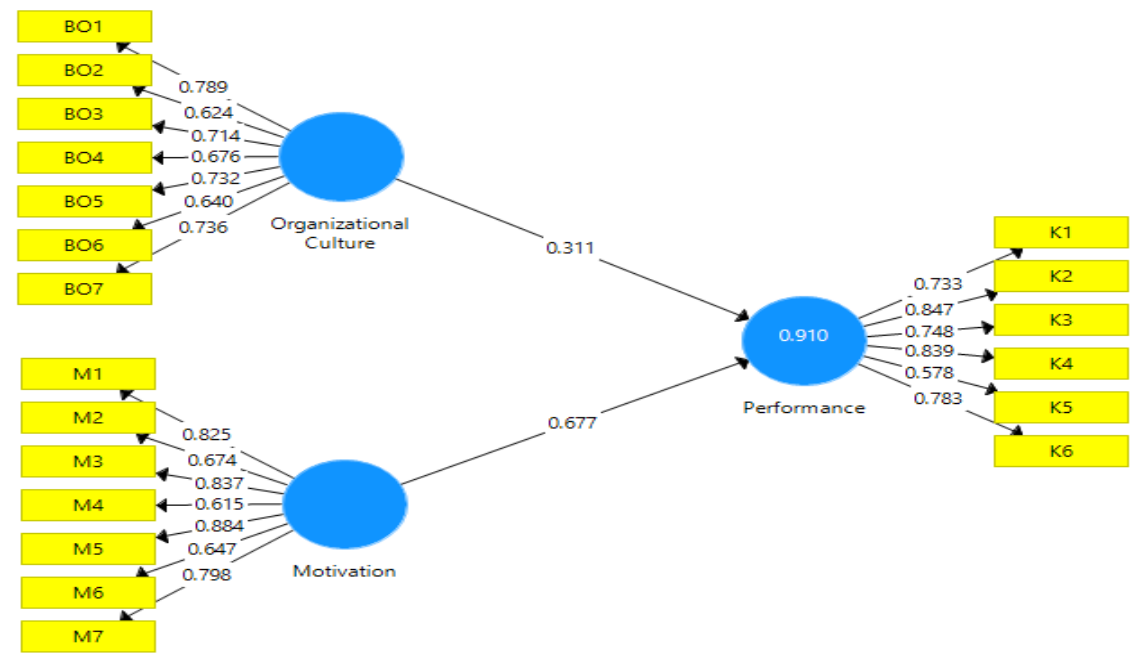

\section{Hasil Uji Hipotesis}

Tabel 9. Hasil Uji Hipotesis

\begin{tabular}{|l|l|l|l|l|}
\hline Variabel & T-Statistics & P-Values & Hipotesis & Keterangan \\
\hline $\mathrm{X} 1=>\mathrm{Y}$ & $9.955>1,679$ & $0,000<0,05$ & $\mathrm{H} 1$ & Diterima \\
\hline $\mathrm{X} 2=>\mathrm{Y}$ & $6,048>1,679$ & $0,000<0,05$ & $\mathrm{H} 2$ & Diterima \\
\hline
\end{tabular}

Sumber: Pengolahan data dengan PLS, 2021

Hipotesis 1 yang menggambarkan pengaruh budaya organisasi terhadap kinerja karyawan memiliki nilai tstastisic 9.955 lebih besar dari nilai t-tabel 1.679 dan tingkat signifikansi lebih kecil dari 5\% yaitu 0.004. Kemudian Hipotesis 2 yang menggambarkan pengaruh motivasi kerja terhadap kinerja karyawan dengan memiliki nilai t-statistic 6.048 lebih besar dari t-tabel 1.679 dan tingkat signifikansi lebih kecil dari 5\% yaitu 0.05 .

\section{Pengaruh budaya organisasi terhadap kinerja pegawai.}

Berdasarkan hasil uji hipotesis budaya organisasi berpengaruh terhadap kinerja pegawai. Hal tersebut ditunjukkan dari hasil uji t-statistic $>t$ tabel $(9,955>1,679)$ dan nilai signifikansi $0,000<0,05$ dengan demikian variabel budaya organisasi (X1) berpengaruh positif terhadap kinerja karyawan. Hal ini sesuai dengan hasil penelitian yang dilakukan oleh (Siti Rahma,2018), dengan penelitian yang berjudul pengaruh pudaya organisasi dan motivasi terhadap kinerja karyawan (Studi Kasus pada PT Telekomunikasi Indonesia Witel Jakarta Selatan Unit Hr\&Cdc Dan Network Area) yang menyatakan pada penelitiannya bahwa terdapat pengaruh positif dan signifikan budaya organisasi terhadap kinerja karyawan.

Berdasarkan hasil dari analisis deskriptif variabel budaya organisasi diperoleh rata-rata sebesar 4,24. Hal tersebut menunjukan bahwa indikator-indikator variabel budaya organisasi memiliki pengaruh terhadap kinerja pegawai. Item pernyataan ke-1 memiliki rata-rata tertinggi sebesar 4,36 dan nilai outernya sebesar 0.812 dengan item pernyataan nya yaitu "Saya selalu berusaha berinovasi dalam bekerja dan siap untuk menanggung resiko jika ada permasalahan". Sedangkan item pernyataan ke-7 memiliki nilai rata-rata terendah sebesar 4,14 dengan nilai outernya sebesar 0.797 dengan item pernyataan yaitu "Saya mampu mempertahankan pertumbuhan perusahan dengan Bekerja sesuai SOP (Standart Operation 
Procedure)".

\section{Pengaruh Motivasi Terhadap Kinerja Karyawan}

Berdasarkan hasil uji hipotesis motivasi berpengaruh terhadap kinerja karyawan. Hal tersebut ditunjukkan dari hasil uji t-statistic $>t$ tabel $(6.048>1,679)$ dan nilai signifikansi $0,000<0,05$ dengan demikian variabel motivasi (X2) berpengaruh positif terhadap kinerja karyawan. Hal ini sesuai dengan hasil penelitian yang dilakukan oleh (Demianus,2017) dengan penelitian yang berjudul pengaruh motivasi kerja, budaya organisasi dan lingkungan kerja terhadap kinerja Karyawan (Studi Pada Karyawan PT. Telkom Witel Papua Barat) yang menyatakan pada penelitiannya bahwa terdapat pengaruh positif dan signifikan motivasi terhadap kinerja karyawan.

Berdasarkan hasil dari analisis deskriptif variabel motivasi diperoleh rata-rata sebesar 4,19. Hal tersebut menunjukan bahwa indikator-indikator variabel motivasi memiliki pengaruh terhadap kinerja karyawan. Item pernyataan ke-3 memiliki rata-rata tertinggi sebesar 4,32 dengan nilai outernya sebesar 0.891 . Item pernyataan nya yaitu "keselarasan antara pimpinan dan bawahan merupakan faktor yang sangat penting untuk menjamin keberhasilan organisasi dalam mencapai tujuan yang telah ditetapkan". Sedangkan item pernyataan ke-7 memiliki nilai rata-rata terendah sebesar 4,1 dengan nilai outernya sebesar 0.794 dengan item pernyataan yaitu "pimpinan di PT Grapari Telkomsel Palangka Raya selalu memberikan penghargaan bagi karyawan yang berhasil mencapai target kerja yang diberikan".

\section{Kesimpulan}

Penelitian dan analisis mengenai pengaruh budaya organisasi dan motivasi terhadap kinerja karyawan pada PT. Grapari Telkomsel di kota Palangka Raya,maka peneliti menyimpulkan bahwa: Budaya organisasi (X1) berpengaruh positif dan signifikan terhadap kinerja karyawan PT Grapari Telkomsel palangka raya. Dan Motivasi (X2) berpengaruh positif dan signifikan terhadap kinerja karyawan.

Hasil penelitian yang dilakukan, maka peneliti memberi saran Kepada pihak PT. Grapari Telkomsel Palangka Raya, hasil penelitian ini untuk meningkatkan kinerja karyawan dengan memperhatikan nilai indikator yang paling rendah dalam penelitian ini.Agar adanya peningkatan kinerja karyawan pada PT Grapari Telkomsel Palangkaraya, perlu adanya kesadaran karyawan akan kepatuhan terhadap SOP dapat di pupuk dengan cara melakukan sosialisasi SOP tidak hanya pada saat karyawan baru masuk saja tetapi secara berkala agar karyawa lebih memahami pentingnya SOP selama bekerja. Bagi pemimpin PT. Grapari sebaiknya memiliki hubungan interpersonal dengan semua karyawan-karyawanya. Tidak hanya kepada karyawan prestasi baik melainkan kepada karyawan yang biasa agar mengeratkan hubungan antar pemimpin dan bawahan, pemimpin masih harus mengembangkan dirinya lagi dalam hal dan pembelajaran ilmu-ilmu dan gaya kepempinan,agar pemimpin harus lebih mengenal dan peka terhadap karyawan dengan memberikan penghargaan serta sistem insentif dan bonus kepada karyawan agar mampu meningkatkan kualitas kerja dan motivasi karyawan.Bagi Peneliti Selanjutnya,dapat menambahkan variabel lain yang dapat memberikan kontribusi terhadap kinerja. Selain itu dapat memberikan metode lain dalam penelitian budaya organisasi dan motivasi terhadap kinerja karyawan.Untuk itu penulis menyarankan kepada penelitian selanjutnya yang 
berhubungan dengan budaya organisasi, motivasi, dan kinerja karyawan dapat melakukan penelitian disektor lainnya sehingga dapat membandingkan hasil penelitian dengan sebelumnya dan peneliti selanjutnya.

\section{Daftar Pustaka}

Abdillah, W., Hartono. (2015). Partial Least Square (PLS). Penerbit Andi. Yogyakarta.

Arikunto. (2016). Prosedur penelitian: suatu penddekatan praktik. Jakarta: PT Rineka Cipta.

Dharma, A, (2012). Manajemen prestasi kerja. Edisi Pertama. Jakarta: Rajawali.

Edy, Sutrisno, (2016). Manajemen sumber daya manusia. Jakarta: Kencana Prenada Media

Darodjat, Tubagus Achmad. (2016). Konsep-konsep dasar manajemen personalia. Bandung: PT. Refika Aditama.

Ghozali, (2012). Partial Least Square: Konsep, Teknik dan Aplikasi smartpls 2.0 M3. Semarang: Badan Penerbit Universitas Diponegoro.

Handoko T. H. (2013). Manajemen personalia dan sumber daya manusia. Yogyakarta: BPFE.

Mangkunegara. (2016). Manajemen Sumber Daya Manusia Perusahaan. Bandung: PT. Remaja Rosdakarya.

Sinambela, Lijan Poltak. 2012. Manajemen Sumber Daya Manusia. PT. Bumi Aksara, Jakarta.

Sugiyono. 2012. Memahami Penelitian kuantitatif. Bandung: Alfabeta.

Sugiyono. 2013. Metode Penelitian Bisnis. Bandung: Alfabeta.

Sugiyono. (2014). Statistika untuk penelitian. Bandung: CV ALFABETA.

Umar. 2011. Metode Penelitian Untuk Skripsi dan Tesis Bisnis Edisi 11. Jakarta: PT Raja Grafindo Persada

Wibowo. (2015). Manajemen kinerja. Jakarta: Penerbit Rajawali Pers.

Wursanto, Drs. Ig, (2014). Dasar-dasar ilmu organisasi. Yogyakarta: Andi Offset

Amstrong, Michael. (2010). Manajemen sumber daya manusia. Jakarta: PT Elexmedia Komputindo.

Edison, Emron. Yohny anwar, Imas komariyah. (2016). Manajemen Sumber Daya Manusia. Bandung: Alfabeta.

Ferdinand, A. (2014). Metode penelitian manajemen. Semarang: Badan Penerbit Universitas Diponegoro.

Hasibuan, Malayu S. P. 2010. Manajemen Sumber Daya Manusia. Jakarta. PT Bumi Aksara

Lako, Andreas. (2011). Kepemimpinan dan kinerja organisasi isu teori dan solusi. Yogyakarta, Amara Books

Robbins, Stephen P \& Judge, Timothy A. 2013. Organizational Behavior Edition

15. New Jersey: Pearson Education

Creswell, J. W. (2014). Research design qualitative, quantitative and mixed method approaches ( $2^{\text {nd }}$ ed). New Delhi: Sage Publications. 
Nawawi, Hadari. (2012). Manajemen sumber daya manusia $\left(5^{\text {th }}\right.$ ed). Yogyakarta: UGM.

Robbins SP, \& Judge. (2010). Perilaku Organisasi (2 ${ }^{\text {nd }}$ ed). Jakarta: Salemba Empat Hal 256.

Tika H. Moh. Pabundu, (2012). Budaya organisasi dan peningkatan kinerja perusahaan, Cetakan Pertama, PT. Bhumi Aksara, Jakarta.

Febrina dan Elva (2017). Pengaruh motivasi kerja dan budaya organisasi terhadap kinerja karyawan pdam tirta tamansari kota madiun. The 9th FIPA: Forum Ilmiah Pendidikan Akuntansi - Universitas PGRI Madiun, 5 (1).

Rahmiati. (2010) Pengaruh Budaya Organisasi dan Motivasi Kerja Terhadap Kinerja Guru di SMKN 2 Padang. Padang: FE UNP.

Tjahjono, H.K. (2014) Budaya organisasional \& balanced scorecard: dimensi Teori dan Praktik. UPFE UMY.

Sedarmayanti. (2011). Manajemen Sumber Daya Manusia, Reformasi Birokrasi

dan Manajemen Pegawai Negeri sipil (cetakan kelima). Bandung PT. Refika Aditama

Demianus. (2017). Pengaruh motivasi kerja, budaya organisasi dan lingkungan kerja terhadap kinerja karyawan (studi pada karyawan pt. Telkom witel papua barat). Jurnal Riset Bisnis dan Manajemen, 3 (4), hlm. 318-331

Destiana, Sisca, et.al. (2015). Pengaruh Pemberian Instentif, Motivasi Kerja Dan Budaya Organisasi Terhadap Kinerja Karyawan (Studi Kasus Pada PT. Bank Rakyat Indonesia (BRI) Cabang Pandanaran Semarang). Jurnal Ilmu Administrasi Bisnis, 4 (2), hlm.

Irawan, Adi Setiyanto. (2017). Pengaruh kepuasan kerja dan komitmen organisasi terhadap turnover intention. Jurnal Akutansi, Ekonomi dan Manajemen Bisnis. 5 (1), hlm. 105 110.

Latief, Baharuddin. (2012). Faktor-faktor yang mempengaruhi kinerja karyawan pt. Mega mulia servindo di makasar. Jurnal Manajemen Dan Akuntansi. 1 (2).

Tumbelaka, Steven Set Xaverius; Alhabsji, Taher; Nimran, Umar. (2016). Pengaruh budaya organisasi terhadap kepuasan kerja, komitmen organisasional dan intention to leave (studi pada karyawan pt. Bitung mina utama). Jurnal Bisnis dan Manajemen. 3 (1), hal. 94-108.

https/Jurnalbisnisdanmanajemen-Pengaruh budaya organisasi terhadap kepuasan kerja, komitmen organisasional dan intention to leave - Bing

Sulaefi. (2019). The influence of organizational culture and work motivation toward employee performance at lestari raharja hospital magelang indonesia. American Scientific Research Journal for Engineering, Technology, and Sciences (ASRJETS), 53 (1), pp 145-163.

Rahma, Siti. (2018). The influence of organizational culture and motivation on employee performance (case study at PT Telekomunikasi Indonesia Witel Jakarta Selatan Unit $H R \& C D C$ and Network Area). Journal of e-Proceedings of Management, 5 (1).

Corresponding author

e-mail: elisabethnauw123@gmail.com 